\title{
Lupus Nephritis Correlates with B-Cell Interferon- $\beta$, Anti-Smith, and Anti-DNA: A Retrospective Study
}

\section{Fatima Alduraibi}

University of Alabama at Birmingham

\section{Huma Fatima}

University of Alabama at Birmingham

Jennie Hamilton

University of Tennessee Health Science Center

\section{W.Winn Chatham}

University of Alabama at Birmingham

\section{Hui-Chen Hsu}

University of Alabama at Birmingham

John Mountz ( $\boldsymbol{D}$ jdmountz@uabmc.edu )

University of Alabama at Birmingham

\section{Research Article}

Keywords: Systemic lupus erythematosus, lupus nephritis, B-cell interferon beta, autoantibodies

Posted Date: November 17th, 2021

DOI: https://doi.org/10.21203/rs.3.rs-1083707/v1

License: (c) (i) This work is licensed under a Creative Commons Attribution 4.0 International License.

Read Full License

Version of Record: A version of this preprint was published at Arthritis Research \&amp; Therapy on April 18th, 2022. See the published version at https://doi.org/10.1186/s13075-022-02766-1. 


\section{Abstract}

Background: In systemic lupus erythematosus (SLE), detection of interferon- $\beta$ (IFN $\beta$ )

in B cells was found to be most prominent in patients with high anti-Smith (Sm) and renal disease, but a mechanistic connection was not clear. The objective of the present study is to determine the association of IFN $\beta$ in peripheral blood naïve B cells with the histopathological features of lupus nephritis (LN).

Methods: The percentage of IFN $\beta^{+}$cells in $\operatorname{IgD}^{+} \mathrm{CD} 27^{-}$naïve $\mathrm{CD} 19^{+} \mathrm{B}$ cells (B-cell IFN $\beta$ ) among peripheral blood mononuclear cells (PBMCs) from 80 SLE patients were analyzed using flow cytometry. Serological and clinical data were collected. The correlations of B-cell IFN $\beta$ with LN classification and with histopathological findings (light, electron and immunofluorescence [IF] microscopic analyses for deposition of IgM, IgG, IgA, C1q, and C3) were determined in 23 available biopsy specimens.

Results: B-cell IFN $\beta$ is positively associated with anti-Sm $(p=0.001)$, anti-DNA $(p=0.010)$, and LN $(p=$ $0.001)$, but was negatively associated with oral/nasal ulcer $(p=0.003)$ and photosensitivity $(p=$ 0.045). B-cell IFN $\beta$ positively correlated with immune complex (IC) deposit in the glomerular basement membrane $(G B M)(p=0.002)$ but not in the mesangial $(p=0.107)$ or tubular region $(p=0.313)$. Patients with high B-cell IFN $\beta$ had statistically increased development of the proliferative LN (Classes III, IV and/or $V)$, compared to patients with low B-cell IFN $(p<0.0001)$. Histopathological features positively associated with increased B-cell IFN $\beta$ included active glomerular lesions as determined by fibrocellular crescents $(p=0.023)$, chronic glomerular lesions indicated by segmental sclerosis $(p=0.033)$, and a membranous pattern of renal damage indicated by spike/holes $(p=0.015)$.

Conclusion: B-cell IFN $\beta$ correlates with severe LN, glomerular basement membrane (GBM) IC deposition, and anatomical features of both active and chronic glomerular lesions.

\section{Background}

Lupus nephritis $(L N)$ results from inflammation through both the innate and adaptive immune responses. (1-3) As with the majority of immune responses, LN is most likely initiated by defects in the innate immune system. $(1,2)$ Supporting this, dysregulations of the type I interferon (IFN) system and related genes (type I interferon stimulated genes - ISG) were identified as being associated with the development of LN in systemic lupus erythematosus (SLE).(4-7) DNA and RNA-protein complexes released from apoptotic or necrotic cells can be taken up by phagocytic cells such as the plasmacytoid dendritic cells (pDCs) to produce type I IFN. $(8,9)$ Type I IFN receptor, which is present on all immune cells as well as parenchymal cells in the target organ of SLE, such as the kidney, lung, vasculature, and skin, can all undergo an inflammatory response after stimulation through the type I IFN receptor.(10)

The adaptive immune response and the development of autoantibodies (autoAbs) have long been recognized as the cardinal feature of SLE. $(9,11-13)$ The same DNA and RNA-protein complexes that promote the innate immune response can trigger the development of B cells producing autoAbs against 
these self-components.(3) We have shown that type I IFN can be produced by and can act upon ribonuclear protein (RNP) autoreactive B cells.(14) Production of autoAbs and certain RNP, such as antiSmith (Sm), anti-SSA and anti-SSB, have been shown to be a "fixed" feature/value of SLE, whereas other autoAbs, such as anti-DNA vary over time and reflect the activity of disease.(15) We have shown that Bcell intracellular interferon beta (IFN $\beta$ ) correlates most strongly with anti-Sm and that the ability to produce type I IFN by B cells can occur in transitional, naïve and memory B cells of SLE patients especially patients who were historically positive with LN.(14) In a mouse model of SLE, the intrinsic production of IFN $\beta$ by $B$ cells does not depend upon the environment and is a fixed feature of enhanced TLR7 signaling and the development of autoreactive B cells.(16) Based on the strong correlation of B-cell IFN $\beta$ with serum anti-Sm and historic positivity of LN in SLE, we correlated IFN $\beta$ in naïve B cells in the peripheral blood mononuclear cell (PBMC) with histopathological features of renal biopsy specimens obtained from the same SLE patients. Our results suggest that high B-cell IFN $\beta$ in SLE patients is most highly associated with $L N$ and serological correlates of $L N$, as well as immune complex (IC) deposition in the glomerular basement membrane (GBM) and anatomical features of both acute and chronic glomerular lesions.

\section{Methods}

\section{Study design}

This is a retrospective cohort study to examine the correlation of the percentage of IFN $\beta$ positive naïve $B$ cells (B-cell IFN $\beta$ ) among SLE and LN patients and compare the clinic-pathologic features and outcomes of high compared to low B-cell IFN $\beta$. All medical records were reviewed at the University of Alabama at Birmingham (UAB). Ethical approval for this study was obtained from the ethics committee at UAB.

\section{Study population}

All patients satisfied the following inclusion criteria: age of onset $\geq 18$ years and confirmed SLE diagnosis by either the American College of Rheumatology (ACR) 1997 revised criteria $(17,18)$ or the 2012 Systemic Lupus International Collaborating Clinics (SLICC) classification criteria.(19) The exclusion criteria were: age < 18 years, or diagnosis of overlap syndrome, mixed connective tissue disease, or other autoimmune diseases. The studies were conducted in compliance with the Helsinki Declaration and approved by the UAB Institutional Review Board. All data were collected in a manner blinded to IFN $\beta$ status until data collection was completed.

\section{Clinical data collection}

Retrospective chart review and data collection were carried out at the time of enrollment visit at the same time of B-cell IFN $\beta$ measurement. Demographic data included age, race and sex. Clinical data included age at the time of diagnosis of SLE/LN, mucocutaneous manifestations of malar rash, discoid rash, photosensitivity, oral/nasal ulcer, arthritis, serositis, lupus nephritis, neurological disorder, and hematologic manifestations of leukopenia, hemolytic anemia, and thrombocytopenia. In addition, 
systemic lupus erythematosus disease activity index (SLEDAI) score, medications used, lupus nephritis class and laboratory data (serum creatinine level, urine protein/creatinine ratio, anti-DNA and anti-Sm antibodies, C3, and C4) were collected. SLEDAI was used to assess SLE severity at time of enrollment visit based on (1) no activity (score: zero); (2) mild activity (score: 1-5); (3) moderate activity (score: 6-10); (4) high activity (score: 11-19); and (4) very high activity (score: $\geq 20$ ). (20) SLE duration was defined as the time between the diagnosis of SLE and enrollment in the study. All clinical variables were recorded as present or absent.

\section{Blood collection for B-cell IFN $\beta$, IgG anti-Sm, and anti-DNA analyses}

Blood samples were collected from patients on the day of enrollment and were evaluated for B-cell IFN $\beta$, circulating $\lg G$ anti-Sm antibodies, and anti-DNA (IgM, $\lg G)$ antibodies. PBMCs were isolated by density gradient centrifugation (Lymphoprep/SepMate, StemCell Technologies).(15)

\section{Flow cytometry enumeration of intracellular IFN $\beta$ in naïve B cells}

Human antibodies included BioLegend BV650-anti-CD27 (O323), PE-Dazzle594-anti-CD19 (HIB19), PerCPCy5.5-anti-CD38 (HB-7); BV605 anti-IgD (IA6-2), and PBL Assay Science FITC-anti-IFN及 (MMHB-3). Dead cells were excluded from analysis using the Fixable APC-eFluor ${ }^{\circledR} 780$ Organic Viability Dye (ThermoFisher) as we previously described.(15)

For determining intracellular IFN $\beta$, cells were stained with ef780 viability dye and surface marker fluorochrome-conjugated antibodies, followed by $2 \%$ paraformaldehyde (PFA) fixation and $70 \%$ ice-cold methanol permeabilization prior to intracellular IFN $\beta$ staining.

Flow cytometry data were acquired using an LSRII FACS analyzer (BD Biosciences) and analyzed with FlowJo software (Tree Star Ashland, OR).

\section{Enzyme-linked immunosorbent assay (ELISA) analysis of autoAbs}

Plasma levels of IgG anti-Sm were determined using a commercially available ELISA kit (Alpco, Salem, $\mathrm{NH}$ ).(15) IgG anti-DNA levels were measured using an established protocol.(21) The reaction was stopped with acidification, and the plate was subsequently read at 450-650 nm using an Emax Precision Microplate Reader (Molecular Device, Sunnyvale, CA, USA).

\section{Renal biopsy}

Renal biopsies were evaluated by a renal pathologist in a blinded manner. The renal biopsies were classified according to the ISN/RPS (2004) classification for LN, which is based on the extent of glomerular involvement by light microscopy, and whether the injury pattern reflects active lesions (endocapillary hypercellularity, neutrophils/karyorrhexis, fibrinoid necrosis, wire-loop lesions, and cellular/fibrocellular crescents) or chronic lesions (global/segmental glomerulosclerosis and fibrous crescents/broad-based adhesions). $(22,23)$ Based on the light microscopic findings, $L N$ was classified as 
follows: minimal mesangial LN (class I), mesangial proliferative LN (class II), focal LN (class III), diffuse LN (class IV), membranous LN (class V), and advanced sclerosing LN (class VI). $(22,23$ )

In addition to active (A) and chronic (C) lesions, the glomerular lesions were characterized as either segmental ( $<50 \%$ glomerular capillary tuft involvement) or global ( $\geq 50 \%$ glomerular capillary tuft involvement). $(23,24)$ The activity and chronicity indices were assessed based on the revised ISN/RPS classification for LN, and in addition to the glomerular lesions included tubulointerstitial inflammation and fibrosis.(23) The disease activity index, based on the presence of active lesions, scored mild (score: <6), moderate (score: 6-12), and severe (score: 12-24). Similarly, the chronicity index, based on the presence of chronic lesions, scored mild (score: <3), moderate (score: 3-6), and severe (score: >6-12).

Each renal biopsy was analyzed by immunofluorescence for immune complex deposits, using antisera for IgG, IgA, IgM, C3, C1q, Kappa light chain, and Lambda light chain. The intensity of immune complex deposits, determined by immunofluorescence, was graded with a score of $0-4+$ for each of the anatomical regions (mesangium, glomerular basement membrane, tubular basement membrane, arteries/ arterioles), with score 0 representing no staining for immune complexes and score $4+$ being the highest.

\section{Statistical analysis}

Statistical analysis was carried out using IBM@ SPSS@ Statistics version 27 (IBM@ Corp., Armonk, NY, USA), and the figures were created using GraphPad Prism 9 software (La Jolla, CA). Principal component analysis (PCA) was used to evaluate IFN $\beta$ data with clinical characteristics of SLE. Numerical data are expressed as mean and standard deviation or median and range, as appropriate. Qualitative data are expressed as frequency and percentage. Comparison between two groups was made using the MannWhitney test or unpaired t-test (two-tailed). A Chi-square test (Fisher's exact test) was used to determine differences in the distribution of a categorical variable. A p-value $<0.05$ was considered significant.

\section{Results}

\section{Patient characteristics}

A total of eighty patients were included in our cohort (Table 1). The mean age at SLE diagnosis was 31.66 years $( \pm 12.82)$, the mean age at the time of enrollment was 41.21 years $( \pm 13.32)$, the mean time between the SLE diagnosis and enrollments to study is $9.93( \pm 6.71)$ years, and the mean time between the renal biopsy obtained and B-cell IFN $\beta$ measurements was $6.63( \pm 1.16)$ years. $69 \%(n=55)$ of the patients were African American, 29\% $(n=23)$ Caucasian, and 2\% $(n=2)$ Hispanic or Latino. 95\% $(n=76)$ were female. The most prevalent clinical features of the SLE patients in our cohort were arthritis in $68 \%$ (n $=54)$, photosensitivity rash in $48 \%(n=38), L N$ in $41 \%(n=33)$, and oral $/$ nasal ulcer in $40 \%(n=32) .58 \%$ $(n=19)$ had proliferative LN either isolated or combined with class II or V. 74\% $(n=59)$ had active disease (SLEDAl score: $\geq 1)$ at the time of enrollment. At this time, 49\% $(n=39)$ had mild (SLEDAl score: 1-5), 20\% $(n=16)$ had moderate (SLEDAl score: $6-10), 1 \%(n=1)$ had high (SLEDAl score: $11-19)$, and $4 \%(n=3)$ 
had very high activity (SLEDAl score: $\geq 20) .89 \%(n=71)$ were on Hydroxychloroquine or Quinacrine or both and $51 \%(n=41)$ were on prednisone at time of enrollment. The mean anti-DNA-IgG (OD) and anti$\mathrm{Sm}$ (unit/ml) at the time of enrollment were $0.34( \pm 0.16), 55( \pm 75.53)$ and $46( \pm 29.40)$, respectively. Sixteen healthy donors were included at the same time.

\section{B-cell IFN $\beta$ in lupus and control groups}

The flow cytometry gating strategy used to determine the percent of IFN $\beta$ positive lgD+CD27-CD38loCD27lo subset of CD19+ naïve B cells is shown in Fig.1A-C. There was a statistically significant increase in B-cell IFN $\beta$ of SLE patients $(n=80$; mean $46.0 \pm 29.4)$ compared to healthy controls $\left(n=16\right.$; mean 14.04 $\left.\pm 13.04 ; p<0.0001^{\star \star * \star}\right)$ (Fig. 1D).

\section{Association of B-cell IFN $\beta$ with SLE clinical features}

Clinical and laboratory features of SLE in 80 patients, along with B-cell IFN $\beta$, were analyzed by principal component analysis (PCA) (Fig. 2). The percentage of IFN $\beta+$ naïve $B$ cells was significantly correlated with anti-Sm $(p=0.001)$ and anti-DNA $(p=0.013)$ (Fig. $2 A$ and $B)$. Patients with nephritis $(p<0.001)$ exhibited a significantly elevated B-cell IFN $\beta$ (Fig. $2 A$ and $C$ ). In contrast, patients with photosensitivity ( $p$ $=0.045$ ) or oral/nasal ulcers $(p=0.003$ ) exhibited a significantly lower B-cell IFN $\beta$ (Fig. 2A, D and E).

\section{Association of B-cell IFN $\beta$ with clinical indicators of $L N$}

Other laboratory indicators of active disease or renal disease, including C3, C4, and urine protein/creatinine ratio, were reviewed/examined at the time of B-cell IFN $\beta$ analysis. There was a negative correlation between B-cell IFN $\beta$ and diminished levels of C3 but not C4 ( $p=0.005, p=0.253$, respectively) (Fig. 3A). There was a near significant correlation between the percentage of B-cell IFN $\beta$ with urine protein/creatinine ratio at the time of enrollment $(p=0.064)(F i g .3 B)$. There was a significant correlation between the B-cell IFN $\beta$ and the SLEDAl score at time of enrollment $(p=0.022)$ (Fig. $3 C)$.

The titer of anti-Sm autoAb has been shown previously to not vary over time in SLE patients.(25) Among the 80 patients, clinical lab measurement of anti-Sm levels at the time near biopsy were available for 53 patients. Consistent with this, there was a highly significant correlation between the levels of anti-Sm near the time of biopsy and at the time of patient enrollment $(p<0.0001)$ (Fig. 3D). There was also a significant correlation between the anti-Sm levels at the time of enrollment and B cell-IFN $\beta$ for these 53 subjects $(p=0.031$ ) (Fig. $3 E$ ). These results suggest that $B$-cell IFN $\beta$ may be a fixed feature in $L N$ patients.

\section{Kidney IC in patients with high or low B-cell IFN $\beta$}

Immune complex deposition can be identified in the GBM, mesangium, tubular region or in the renal artery in LN.(26) We next determined if B-cell IFN $\beta$ could be associated with renal IC deposition. Renal biopsy specimens were obtained from 23 available specimens among the 80 SLE patients. SLE patients were divided into two groups, determined by having B-cell IFN $\beta$ below the mean (IFN $\beta$ Iow, $n=10$ ) and above 
the mean (IFN $\beta$ high, $n=13$ ). The staining for all the immunoreactants i.e., IgG, IgA, IgM, Kappa, Lambda, $\mathrm{C} 3$, and $\mathrm{C} 1 \mathrm{q}$ was increased along the GBM in the biopsy of patients with high B-cell IFN $\beta$, compared to patients with low B-cell IFN $\beta$ ( $p=0.002$ ), indicating increased deposition of IC in the former category of the lupus patients Fig. 4A. Although the IC in the mesangium and tubules of the biopsy of the high B-cell IFN $\beta$ group was more prevalent compared to the low B-cell IFN $\beta$ group; this did not reach statistical significance ( $p=0.107, p=0.313$, respectively) (Fig. 4B and $C$ ). IC deposition was rare in the arterioles/arteries in our cohort of lupus patients, but when observed, it was almost exclusively present in the high B-cell IFN $\beta$ subgroup and was statistically significant $(p=0.001)$ (Fig. 4D).

We concluded that increased IC deposits along the GBM of the high B-cell IFN $\beta$ SLE patients compared to low B-cell IFN $\beta$ SLE patients is consistent with the finding that B-cell IFN $\beta$ positively correlates with antiSm (Fig. 2A and B) at the time of enrollment and also at the time of measurement in a clinical lab (Fig. $3 \mathrm{E})$.

\section{Association of B-cell IFN $\beta$ with the classification of LN}

To determine whether $L N$ classification correlated with B-cell IFN $\beta$, we compared LN classification from the available 33 SLE patients in our cohort. Patients in the high B-cell IFN $\beta$ group exhibited a greater tendency to develop class III and IV +/- class V LN compared to patients in the low B-cell IFN $\beta$ group (Fig. $5 A)$. These results together suggest that patients with higher percentage of IFN $\beta$ + naïve $B$ cells tend to develop more severe LN.

\section{Association of B-cell IFN $\beta$ with histopathologic features of LN}

Renal disease histopathological features were further analyzed from 23 available specimens from the present cohort. The histology slides were not available for 10 patients, as the biopsies were performed outside the present institution.

A comprehensive analysis was carried out to determine the association of the presence or absence of 12 different histologic features present at the time of biopsy with B-cell IFN $\beta$ (Fig. 5B and F). These histologic features were divided as active glomerular and chronic glomerular lesions.(23) There was a significant difference in B-cell IFN $\beta$ in SLE patients with or without fibrocellular crescents, segmental sclerosis, and chronicity index $(p=0.023, p=0.033, p=0.033$, respectively) (Fig. 5B and $D)$. In addition, we found that the membranous pattern manifested as spikes and holes by light microscopy, was statistically significant $(p=0.015)$ (Fig. $5 E$ ). There was no significant difference in B-cell IFN $\beta$ in patients with or without tubulointerstitial lesions, acute tubular injury or interstitial fibrosis and tubular atrophy (Fig. 5F).

\section{Discussion}

LN has been shown to be strongly correlated with anti-Sm.(15) The results suggest that B-cell IFN $\beta$ is most strongly associated with the levels of an autoAb that have been found to be stable over time. The 
present findings suggest that B-cell IFN $\beta$ may be one factor underlying development of anti-Sm which in turn leads to renal disease by forming IC or direct binding to Sm or other autoantigens in the kidney, as previously proposed.(14) Alternatively, we have shown that expression of IFN $\beta$ in naïve B cells is strongly correlated with intracellular IFN $\beta$ detected in all subpopulations of B cells, including transitional $B$ cells, memory B cells, as well as in plasmacytoid dendritic cells in PBMC.(15) Previous investigators have shown that type I IFN produced by tubular cells in the kidney is associated with LN.(27) Another possibility is that IFN $\beta$ produced in B cells reflects the ability of IFN $\beta$ produced in other cells such as renal tubular cells. We are currently analyzing this possibility in renal biopsy samples from SLE patients.

The mechanism of renal disease by these antibodies is through their ability to form IC that can be found in the glomerulus or interstitium of the kidney or by binding to cross-reactive antigenic targets in the kidney.(28) The primary function of complement component C3 in prevention of IC-mediated disease in SLE is its ability to break down or diminish the size of ICs by displacing autoAbs and its subsequent function in enhancing uptake of ICs by phagocytic cells that can degrade these complexes.(3) It has been proposed that low levels of $\mathrm{C} 3$ is one of the main factors that lead to IC formation and IC localization in the kidney.(29) Also, genetically determined deficiencies of C3 are well known predisposing factors for SLE, but more recently, genetically determined factors leading to modestly low levels of C3 have been proposed as a factor leading to IC in renal disease in SLE.(30) We propose that the combined production of autoAbs, resulting in part from high B-cell IFN $\beta$, and low C3 complement levels, also genetically determined, can together predispose to $L N$.

Type I IFN has previously been found to mediate LN from the initial stages to the development of renal fibrosis. $(27,31)$ At the initial stages, type I IFN contributes to formation of IC as well as decreased clearance of ICs.(32) It has been shown that renal resident cells rather than infiltrating immune cells are a main source of type I IFN(31) and can be stimulated through TLR by way of nucleic acid products including DNA and RNA-immune complexes which can induce IFN $\beta$ in renal medullary cells (RMC).(9, 33) Thus, IFN $\beta$ can have a dual factor of inducing IC, as well as decreasing clearance of ICs at the acute stage.

The present results also suggest that high type I IFN promotes chronic changes such as glomerular sclerosis. $(34,35)$ Previous results have shown that IFN $\beta$ can stimulate podocyte actin B-1 expression and actin remodeling(36) while IFNa has been shown to accelerate glomerular epithelial cells dysfunction and cause epithelial cell apoptosis which increases glomerular epithelial cell permeability.(37) Type I IFN also has been shown to promote renal medullary cells and lead to glomerular fibrosis through hyperplasia and proliferation through the induction of metalloproteinases and growth factors.(38) We previously showed that type I IFN can enhance "stiffness" of macrophages.(39) In the kidney, development of renal myofibroblasts which leads to excessive accumulation of extracellular matrix is a common feature of chronic renal disease. $(40,41)$ The pathogenicity of type I IFN in LN therefore can be multifaceted. Indeed, the present results indicated that patients with more aggressive LN also exhibited higher B-cell IFN $\beta$ in the periphery. 
A remaining question is how peripheral B-cell IFN $\beta$ exhibits such a strong and positive correlation with LN despite the different timing of specimen collections. Paradoxically, B-cell IFN $\beta$ negatively correlates with photosensitivity and oral/nasal ulcer. The present unsupervised comprehensive analysis of organassociated lesions in 80 SLE patients is in agreement with results by others that patients with active discoid lupus rarely exhibit progressive renal disease.(42-44) These results are also consistent with recent findings by others showing that type I IFN activity is highly associated with active LN but has weak association with photosensitivity and mucocutaneous lupus.(45) The same study further shows that type I IFN is highly associated with the development of anti-Sm and ANA but has weak or no association with the development of non-RNP autoantibodies.(45) These results together suggest that high B-cell IFN $\beta$ is a persistent feature of some SLE patients enabling the development of anti-Sm forming B cells.

The limitation of this study is that it is a retrospective study of LN biopsy specimens, with renal biopsy samples available for only 23 of the enrolled patients. A prospective longitudinal study will be needed to determine if B-cell IFN $\beta$ predicts the onset or severity of LN. In addition, specific clinical information and labs (urine protein/creatinine ratio, anti-DNA, anti-Sm, and treatment details) were not available for some biopsied patients, and assessments for IFN $\beta$ were not contemporaneous with renal biopsy.

\section{Conclusions}

In summary, the results suggest that high percentages of IFN $\beta^{+}$in naïve B cells in SLE patients are associated with severe LN and serological correlates of nephritis, as well as IC deposition and anatomical features of both active and chronic glomerular lesions. These results provide insights into the pathogenic mechanisms of B-cell IFN $\beta$ with regard to the production of autoAbs, immune complexes, and renal tissue disease damage that can help guide future therapies that target type I IFN for the treatment of SLE.

\section{List Of Abbreviations}

SLE: Systemic lupus erythematosus

IFN $\beta$ : interferon- $\beta$

Sm: anti-Smith

LN: lupus nephritis

IF: Immunofluorescence

GBM: Glomerular basement membrane

IC: Immune complex

IFN: Interferon 
pDCs: Plasmacytoid dendritic cells

autoAbs: Autoantibodies

RNP: Ribonuclear protein

IFN $\beta$ : Intracellular interferon beta

PBMC: Peripheral blood mononuclear cell

B-cell IFNß: IFN $\beta$ positive naïve $B$ cells

UAB: University of Alabama at Birmingham

ACR: American College of Rheumatology

SLICC: Systemic Lupus International Collaborating Clinics

SLEDAl: Systemic lupus erythematosus disease activity index

PFA: Paraformaldehyde

PCA: Principal component analysis

RMC: Renal medullary cells

\section{Declarations}

\section{Ethics approval and consent to participate}

Ethics approval was granted by the University of Alabama at Birmingham Institutional Review Boards. Informed consent was obtained from each participant and all samples and data were coded to maintain the anonymity of all patients.

\section{Consent for publication}

Not applicable

\section{Availability of data and materials}

The datasets used and/or analysed during the current study are available from the corresponding author on reasonable request.

\section{Competing interests}

The Authors declare that there is no conflict of interest. 


\section{Funding}

This work was supported by the VA Merit Review grant [I01BX004049]; the NIH grants [R01-AI-071110, R01 Al134023], the Lupus Research Alliance Distinguished Innovator Award; the LRA Target Identification in Lupus Award; and grants to support flow cytometry analysis [P30-AR-048311 and P30-Al-027767]. Funders had no role in design, analysis, and reporting.

\section{Authors' contributions}

$\mathrm{FA}, \mathrm{HF}, \mathrm{JAH}, \mathrm{HCH}$ and JDM were responsible for methodology, validation, formal analysis and visualization. $\mathrm{FA}, \mathrm{HCH}$ and JDM were responsible for the conception of the research idea and writingOriginal Draft. HF, JAH and WWC were responsible for writing - review \& editing. HF, WWC, HCH and JDM were responsible for the supervision. $\mathrm{HCH}$ and JDM were responsible for the funding acquisition. All authors reviewed the manuscript.

\section{Acknowledgements}

The authors wish to thank Dr. Kevin Pawlik and Dr. Kellie Warren for their careful proofreading of the manuscript.

\section{References}

1. Arazi A, Rao DA, Berthier CC, Davidson A, Liu Y, Hoover PJ, et al. The immune cell landscape in kidneys of patients with Lupus nephritis. Nat Immunol. 2019;20(7):902-14.

2. Maria NI, Davidson A. Renal Macrophages and Dendritic Cells in SLE Nephritis. Curr Rheumatol Rep. 2017;19(12):81.

3. Birmingham DJ, Hebert LA. The Complement System in Lupus Nephritis. Semin Nephrol. 2015;35(5):444-54.

4. Bengtsson AA, Sturfelt G, Truedsson L, Blomberg J, Alm G, Vallin H, et al. Activation of type I interferon system in systemic lupus erythematosus correlates with disease activity but not with antiretroviral antibodies. Lupus. 2000;9(9):664-71.

5. Rönnblom L, Alm GV. An etiopathogenic role for the type I IFN system in SLE. Trends Immunol. 2001;22(8):427-31.

6. Baechler EC, Batliwalla FM, Karypis G, Gaffney PM, Ortmann WA, Espe KJ, et al. Interferon-inducible gene expression signature in peripheral blood cells of patients with severe lupus. Proc Natl Acad Sci U S A. 2003;100(5):2610-5.

7. Landolt-Marticorena C, Bonventi G, Lubovich A, Ferguson C, Unnithan T, Su J, et al. Lack of association between the interferon-alpha signature and longitudinal changes in disease activity in systemic lupus erythematosus. Ann Rheum Dis. 2009;68(9):1440-6.

8. Lyn-Cook BD, Xie C, Oates J, Treadwell E, Word B, Hammons G, et al. Increased expression of Toll-like receptors (TLRs) 7 and 9 and other cytokines in systemic lupus erythematosus (SLE) patients: ethnic 
differences and potential new targets for therapeutic drugs. Mol Immunol. 2014;61(1):38-43.

9. Komatsuda A, Wakui H, Iwamoto K, Ozawa M, Togashi M, Masai R, et al. Up-regulated expression of Toll-like receptors mRNAs in peripheral blood mononuclear cells from patients with systemic Lupus erythematosus. Clin Exp Immunol. 2008;152(3):482-7.

10. de Weerd NA, Nguyen T. The interferons and their receptors-distribution and regulation. Immunol Cell Biol. 2012;90(5):483-91.

11. Higgs BW, Liu Z, White B, Zhu W, White WI, Morehouse C, et al. Patients with systemic lupus erythematosus, myositis, rheumatoid arthritis and scleroderma share activation of a common type I interferon pathway. Ann Rheum Dis. 2011;70(11):2029-36.

12. Rönnblom L, Alm GV, Eloranta ML. The type I interferon system in the development of lupus. Semin Immunol. 2011;23(2):113-21.

13. Lande R, Ganguly D, Facchinetti V, Frasca L, Conrad C, Gregorio J, et al. Neutrophils activate plasmacytoid dendritic cells by releasing self-DNA-peptide complexes in systemic lupus erythematosus. Sci Transl Med. 2011;3(73):73ra19.

14. Hamilton JA, Hsu HC, Mountz JD. Role of production of type I interferons by B cells in the mechanisms and pathogenesis of systemic lupus erythematosus. Discov Med. 2018;25(135):21-9.

15. Hamilton JA, Wu Q, Yang P, Luo B, Liu S, Li J, et al. Cutting Edge: Intracellular IFN- $\beta$ and Distinct Type I IFN Expression Patterns in Circulating Systemic Lupus Erythematosus B Cells. J Immunol. 2018;201(8):2203-8.

16. Hamilton JA, Hsu HC, Mountz JD. Autoreactive B cells in SLE, villains or innocent bystanders? Immunol Rev. 2019;292(1):120-38.

17. Hochberg MC. Updating the American College of Rheumatology revised criteria for the classification of systemic lupus erythematosus. Arthritis Rheum. 1997;40(9):1725.

18. Tan EM, Cohen AS, Fries JF, Masi AT, McShane DJ, Rothfield NF, et al. The 1982 revised criteria for the classification of systemic lupus erythematosus. Arthritis Rheum. 1982;25(11):1271-7.

19. Hartman EAR, van Royen-Kerkhof A, Jacobs JWG, Welsing PMJ, Fritsch-Stork RDE. Performance of the 2012 Systemic Lupus International Collaborating Clinics classification criteria versus the 1997 American College of Rheumatology classification criteria in adult and juvenile systemic lupus erythematosus. A systematic review and meta-analysis. Autoimmun Rev. 2018;17(3):316-22.

20. Bombardier C, Gladman DD, Urowitz MB, Caron D, Chang CH. Derivation of the SLEDAI. A disease activity index for lupus patients. The Committee on Prognosis Studies in SLE. Arthritis Rheum. 1992;35(6):630-40.

21. Mountz JD, Yang P, Wu Q, Zhou J, Tousson A, Fitzgerald A, et al. Genetic segregation of spontaneous erosive arthritis and generalized autoimmune disease in the BXD2 recombinant inbred strain of mice. Scand J Immunol. 2005;61(2):128-38.

22. Weening JJ, D'Agati VD, Schwartz MM, Seshan SV, Alpers CE, Appel GB, et al. The classification of glomerulonephritis in systemic lupus erythematosus revisited. J Am Soc Nephrol. 2004;15(2):241-50. 
23. Bajema IM, Wilhelmus S, Alpers CE, Bruijn JA, Colvin RB, Cook HT, et al. Revision of the International Society of Nephrology/Renal Pathology Society classification for lupus nephritis: clarification of definitions, and modified National Institutes of Health activity and chronicity indices. Kidney Int. 2018;93(4):789-96.

24. Grootscholten C, Bajema IM, Florquin S, Steenbergen EJ, Peutz-Kootstra CJ, Goldschmeding R, et al. Interobserver agreement of scoring of histopathological characteristics and classification of Lupus nephritis. Nephrol Dial Transplant. 2008;23(1):223-30.

25. McCarty GA, Rice JR, Bembe ML, Pisetsky DS. Independent expression of autoantibodies in systemic Lupus erythematosus. J Rheumatol. 1982;9(5):691-5.

26. Nangaku M, Couser WG. Mechanisms of immune-deposit formation and the mediation of immune renal injury. Clin Exp Nephrol. 2005;9(3):183-91.

27. Der E, Suryawanshi H, Morozov P, Kustagi M, Goilav B, Ranabothu S, et al. Tubular cell and keratinocyte single-cell transcriptomics applied to lupus nephritis reveal type I IFN and fibrosis relevant pathways. Nat Immunol. 2019;20(7):915-27.

28. Liu Y, Anders HJ. Lupus nephritis: from pathogenesis to targets for biologic treatment. Nephron Clin Pract. 2014;128(3-4):224-31.

29. Leffler J, Bengtsson AA, Blom AM. The complement system in systemic lupus erythematosus: an update. Ann Rheum Dis. 2014;73(9):1601-6.

30. Bao L, Cunningham PN, Quigg RJ. Complement in Lupus Nephritis: New Perspectives. Kidney Dis (Basel). 2015;1(2):91-9.

31. Ding $X$, Ren Y, He X. IFN-I mediates Lupus nephritis from the beginning to renal fibrosis. Front Immunol. 2021;12:676082.

32. Ivashkiv LB, Donlin LT. Regulation of type I interferon responses. Nat Rev Immunol. 2014;14(1):36-49.

33. Patole PS, Pawar RD, Lech M, Zecher D, Schmidt H, Segerer S, et al. Expression and regulation of Tolllike receptors in lupus-like immune complex glomerulonephritis of MRL-Fas(Ipr) mice. Nephrol Dial Transplant. 2006;21(11):3062-73.

34. Datta D, Contreras AG, Grimm M, Waaga-Gasser AM, Briscoe DM, Pal S. Calcineurin inhibitors modulate CXCR3 splice variant expression and mediate renal cancer progression. J Am Soc Nephrol. 2008;19(12):2437-46.

35. Yoshikawa M, Nakayamada S, Kubo S, Nawata A, Kitanaga Y, Iwata S, et al. Type I and II interferons commit to abnormal expression of chemokine receptor on B cells in patients with systemic lupus erythematosus. Clin Immunol. 2019;200:1-9.

36. Gurkan S, Cabinian A, Lopez V, Bhaumik M, Chang JM, Rabson AB, et al. Inhibition of type I interferon signalling prevents TLR ligand-mediated proteinuria. J Pathol. 2013;231(2):248-56.

37. Thacker SG, Berthier CC, Mattinzoli D, Rastaldi MP, Kretzler M, Kaplan MJ. The detrimental effects of IFN-alpha on vasculogenesis in Lupus are mediated by repression of IL-1 pathways: potential role in atherogenesis and renal vascular rarefaction. J Immunol. 2010;185(7):4457-69. 
38. Triantafyllopoulou A, Franzke CW, Seshan SV, Perino G, Kalliolias GD, Ramanujam M, et al. Proliferative lesions and metalloproteinase activity in murine Lupus nephritis mediated by type I interferons and macrophages. Proc Natl Acad Sci U S A. 2010;107(7):3012-7.

39. Li H, Fu YX, Wu Q, Zhou Y, Crossman DK, Yang P, et al. Interferon-induced mechanosensing defects impede apoptotic cell clearance in Lupus. J Clin Invest. 2015;125(7):2877-90.

40. Liu Y. Renal fibrosis: new insights into the pathogenesis and therapeutics. Kidney Int. 2006;69(2):213-7.

41. Humphreys BD, Lin SL, Kobayashi A, Hudson TE, Nowlin BT, Bonventre JV, et al. Fate tracing reveals the pericyte and not epithelial origin of myofibroblasts in kidney fibrosis. Am J Pathol. 2010;176(1):85-97.

42. Vera-Recabarren MA, Garcia-Carrasco M, Ramos-Casals M, Herrero C. Comparative analysis of subacute cutaneous Lupus erythematosus and chronic cutaneous Lupus erythematosus: clinical and immunological study of 270 patients. Br J Dermatol. 2010;162(1):91-101.

43. Merola JF, Chang CA, Sanchez MR, Prystowsky SD. Is chronic cutaneous discoid lupus protective against severe renal disease in patients with systemic lupus erythematosus? J Drugs Dermatol. 2011;10(12):1413-20.

44. Santiago-Casas Y, Vilá LM, McGwin G, Jr., Cantor RS, Petri M, Ramsey-Goldman R, et al. Association of discoid lupus erythematosus with clinical manifestations and damage accrual in a multiethnic lupus cohort. Arthritis Care Res (Hoboken). 2012;64(5):704-12.

45. Oke V, Gunnarsson I, Dorschner J, Eketjäll S, Zickert A, Niewold TB, et al. High levels of circulating interferons type I, type II and type III associate with distinct clinical features of active systemic lupus erythematosus. Arthritis Res Ther. 2019;21(1):107.

\section{Tables}

Table 1. Baseline clinical characteristics of the participants at the time of enrollment 


\begin{tabular}{|c|c|}
\hline Characteristics & Total patients ( $N=80,100 \%)$ \\
\hline Age at time of enrollment-year, mean (SD) & $41.21( \pm 13.32)$ \\
\hline Age at time of diagnosis of SLE-year, mean (SD) & $31.66( \pm 12.82)$ \\
\hline SLE duration-year, mean (SD) & $9.93( \pm 6.71)$ \\
\hline \multicolumn{2}{|l|}{ Race } \\
\hline Caucasian & $23(29)$ \\
\hline African American & $55(69)$ \\
\hline Hispanic or Latino & $2(2)$ \\
\hline \multicolumn{2}{|l|}{ Sex } \\
\hline Female & $76(95)$ \\
\hline Male & $4(5)$ \\
\hline \multicolumn{2}{|l|}{ Clinical features } \\
\hline \multicolumn{2}{|l|}{ Cutaneous disorder } \\
\hline Malar rash & $27(34)$ \\
\hline Discoid rash & $12(15)$ \\
\hline Photosensitivity & $38(48)$ \\
\hline Oral/nasal ulcers & $32(40)$ \\
\hline Arthritis & $54(68)$ \\
\hline Serositis (pleuritic, pericarditis) & $18(23)$ \\
\hline Lupus nephritis & $33(41)$ \\
\hline Autoimmune hepatitis & $1(1)$ \\
\hline Pancreatitis & $1(1)$ \\
\hline Cardiomyopathy & $1(1)$ \\
\hline ILD & $1(1)$ \\
\hline Neurological disorder (psychosis, seizure, CNS vasculitis) & $7(9)$ \\
\hline \multicolumn{2}{|l|}{ Hematological disorder } \\
\hline Hemolytic anemia & $4(5)$ \\
\hline Leukopenia & $20(25)$ \\
\hline Thrombocytopenia & $16(20)$ \\
\hline
\end{tabular}




\begin{tabular}{|c|c|}
\hline \multicolumn{2}{|l|}{ SLEDAI (score) } \\
\hline No activity (0) & $18(23)$ \\
\hline Mild (1-5) & $39(49)$ \\
\hline Moderate (6-10) & $16(20)$ \\
\hline High activity (11-19) & $1(1)$ \\
\hline Very high activity $(\geq 20)$ & $3(4)$ \\
\hline Missing, (\%) & $3(4)$ \\
\hline \multicolumn{2}{|l|}{ Medication at time of enrollment } \\
\hline Hydroxychloroquine, Quinacrine or both & $71(89)$ \\
\hline Prednisone & $41(51)$ \\
\hline MTX or Leflunomide & $19(24)$ \\
\hline MMF, Myfortic or AZA & $19(24)$ \\
\hline Belimumab & $11(14)$ \\
\hline \multicolumn{2}{|l|}{ Immunology laboratory results } \\
\hline Anti-DNA (titer), mean (SD) & $36( \pm 58.13)$ \\
\hline Anti-DNA- IgM (OD), mean (SD) & $0.24( \pm 0.12)$ \\
\hline Anti-DNA- IgG (OD) mean (SD) & $0.34( \pm 0.16)$ \\
\hline Anti-Smith (unit/mL), mean (SD) & $55( \pm 75.53)$ \\
\hline Anti-Smith (unit) at any time, mean (SD) & $68.7( \pm 143.78)$ \\
\hline C3 (mg/dL), mean (SD) & $118( \pm 32.40)$ \\
\hline $\mathrm{C} 4(\mathrm{mg} / \mathrm{dL})$, mean $(\mathrm{SD})$ & $23( \pm 11.22)$ \\
\hline \% of IFNß-naïve B cells, mean (SD) & $46( \pm 29.40)$ \\
\hline \multicolumn{2}{|l|}{ Lupus nephritis class } \\
\hline Class I & $1(1)$ \\
\hline Class II & $9(11)$ \\
\hline Class III & $5(6)$ \\
\hline Class IV & $6(7)$ \\
\hline Class V & $4(5)$ \\
\hline Class II and III & $1(1)$ \\
\hline
\end{tabular}


SLE: Systemic lupus erythematosus; ILD: Interstitial lung disease; CNS: Central nervous system; SLEDAl: Systemic Lupus Erythematosus Disease Activity Index; HCQ: Hydroxychloroquine; MTX: Methotrexate; AZA: Azathioprine; MMF: Mycophenolate mofetil; Myfortic: Mycophenolic acid.

\section{Figures}

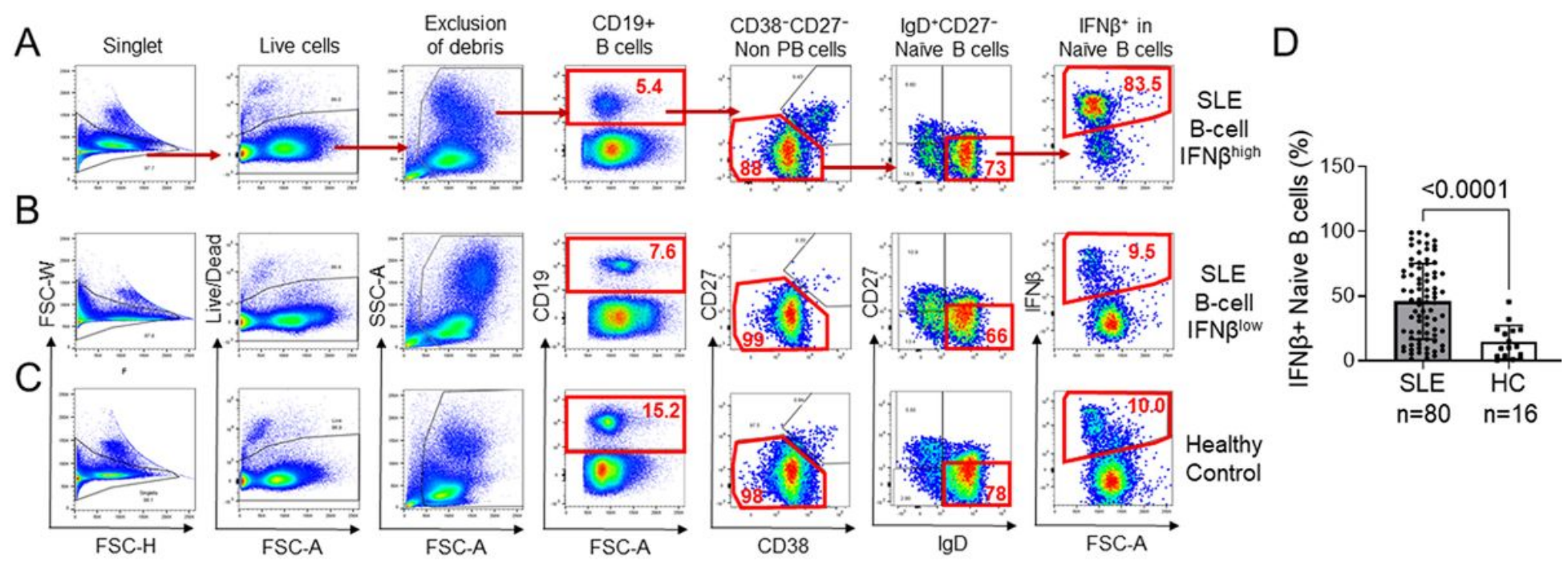

\section{Figure 1}

Flow cytometry analysis of IFN $\beta+$ naïve B cells. $(A, B, C)$ Flow cytometry plots showing the sequential gating of IFN $\beta$ in naïve $B$ cells based on the indicated cell surface markers in a representative SLE patient with high B-cell IFN $\beta(A)$, a representative SLE patient with low B-cell IFN $\beta(B)$, and a representative healthy control donor (C). (D) Bar graph showing the percentage of IFN $\beta+$ naïve B cells in SLE patients and healthy controls (PB, plasmablasts/plasma cells, $\mathrm{HC}$; healthy control)(Data are mean $\pm \mathrm{SD}$; unpaired t-test). 

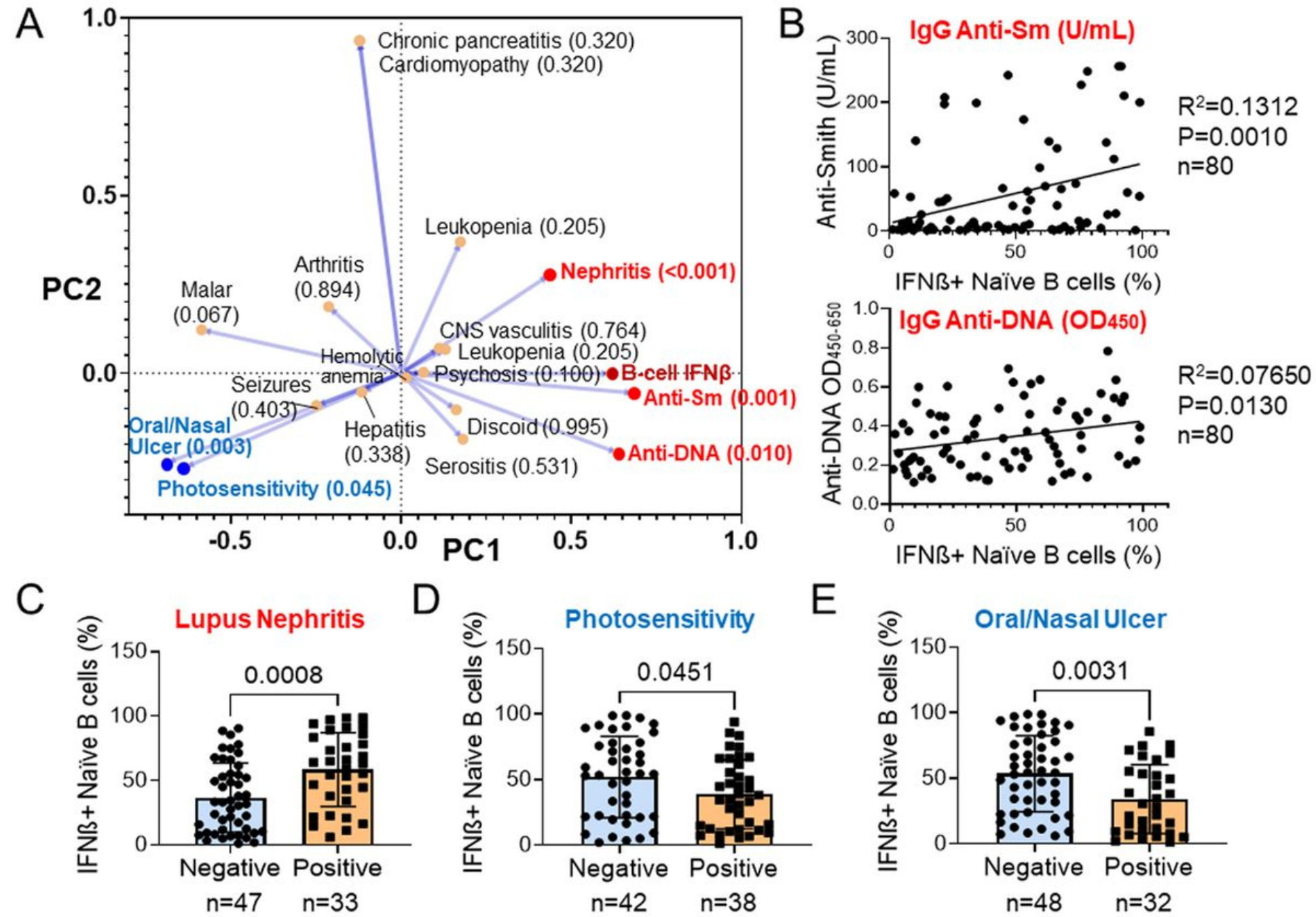

Figure 2

Association of clinical and laboratory parameters with B-cell IFN $\beta$ in SLE patients. Eighty SLE patients were analyzed for B-cell IFN $\beta$ and other clinical and laboratory characteristics. (A) Principal component (PC) analysis of 18 parameters and B-cell IFN $\beta$. The clinical parameters indicated near the position of the $P C$ chart and the $p$ value of each parameter as being associated with B-cell IFN $\beta$ is shown in the parenthesis. Variants shown in red bold exhibit significant positive correlation with B-cell IFN $\beta$. Variants shown in bold blue exhibit significant negative correlation with B-cell IFNR. (B) Linear regression analysis of anti-Smith (top) and anti-DNA (bottom) with B-cell IFN $\beta$. Anti-Sm was shown as $\mathrm{U} / \mathrm{mL}$. Anti-DNA was shown as OD450. R2, $p$ value, and number of subjects ( $n$ ) are indicated. (C, D, E) Bar graph showing the percentage of IFN $\beta+$ naïve B cells in SLE patients with (positive) or without (negative) LN (C), photosensitivity (D), and oral/nasal ulcer $(E)($ mean $\pm S D$; Unpaired t-test with the $p$ value shown in each panel). 


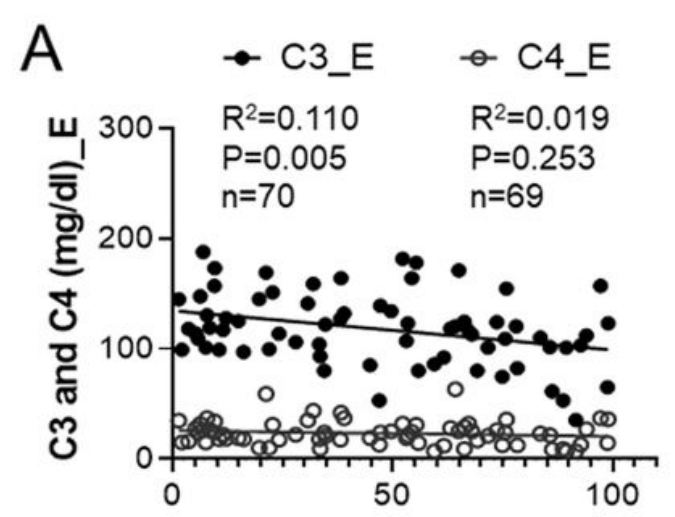

IFNß+ Naïve B cells (\%)

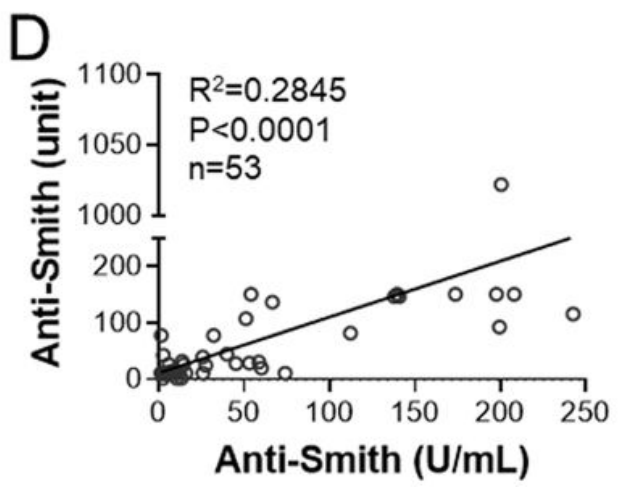

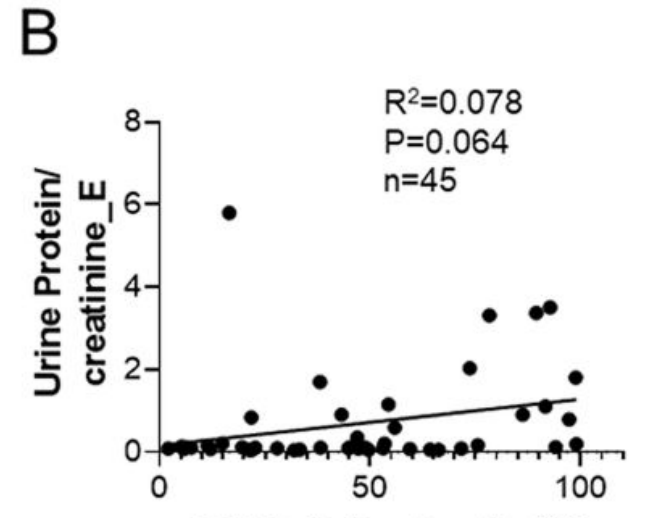

IFNß+ Naïve B cells (\%)

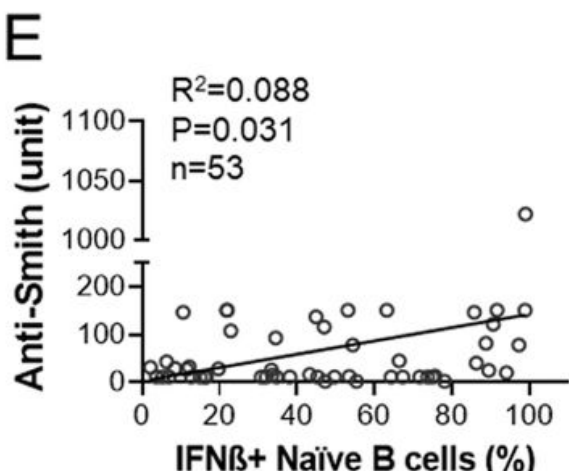

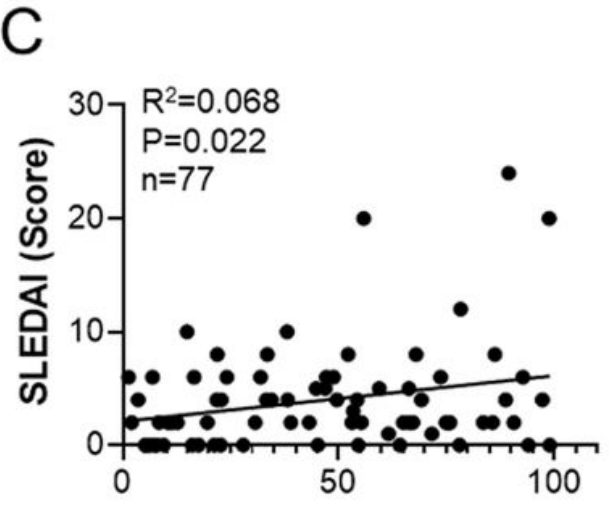

IFNß+ Naïve B cells (\%)

Figure 3

Association of B-cell IFN $\beta$ with LN-related laboratory parameters and SLEDAI. (A) Complement C3 $(\mathrm{mg} / \mathrm{dL})$ and $\mathrm{C} 4(\mathrm{mg} / \mathrm{dL})$ at the time of enrollment were plotted against the percentage of IFN $\beta+$ naïve $B$ cells. (B) Urinary protein/creatinine ratio at the time of enrollment was plotted against the percentage of IFN $\beta+$ naïve B cells. (C) SLEDAI score was plotted against the percentage of IFN $\beta+$ naïve B cells. (D) AntiSm (unit) at any time was plotted against anti-Sm at the time of enrollment. (E) Anti-Sm (unit) at any time was plotted against the percentage of IFN $\beta+$ naïve $B$ cells (Linear regression analysis. The R2, $p$ value, and the number of subjects are shown on the plot). 

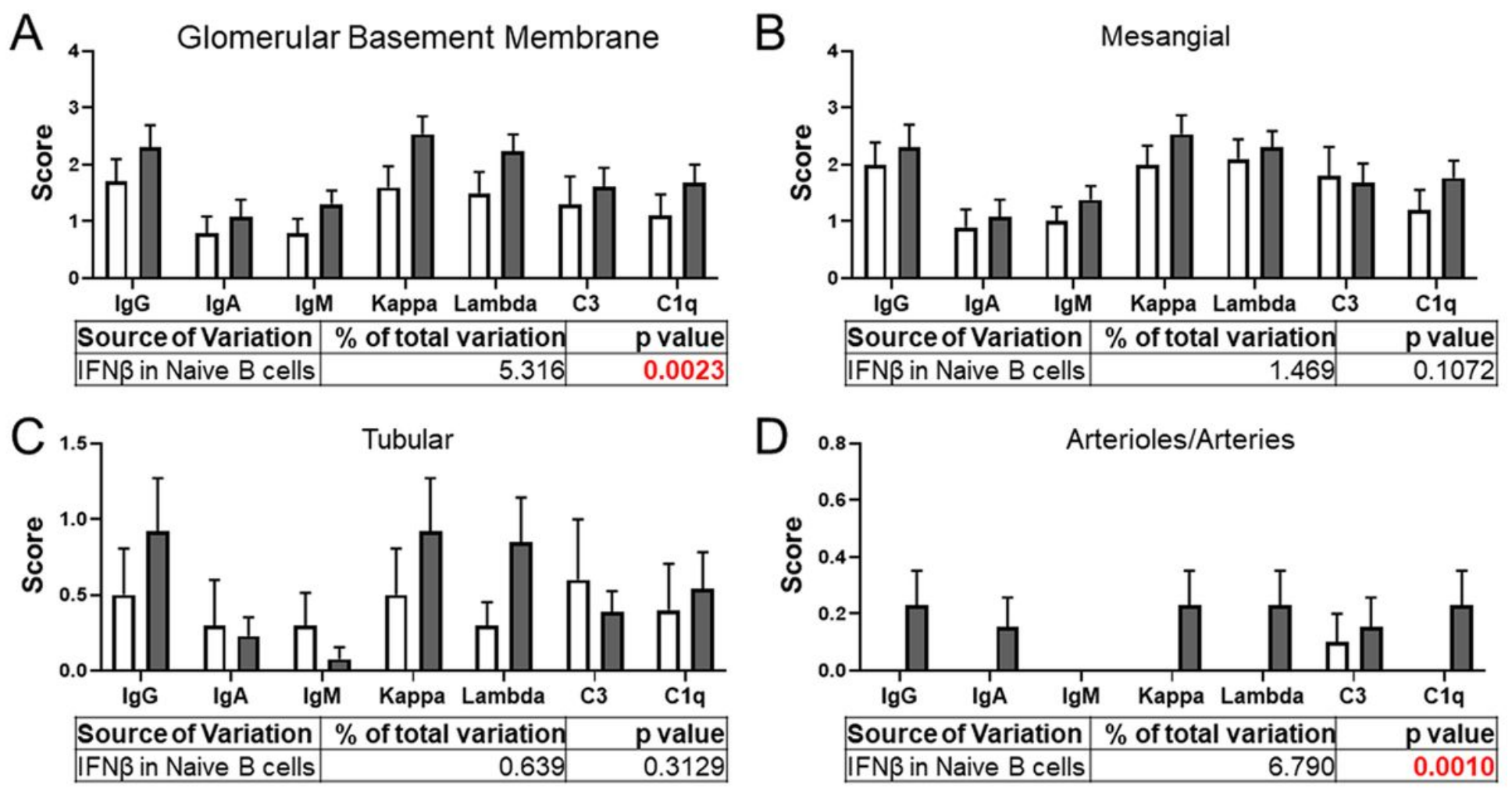

Figure 4

Association of B-cell IFN $\beta$ with immune complex location in renal biopsy. Renal biopsies were obtained from 23 available specimens. The immune complexes were scored based on the presence each indicated type in the glomerular basement membrane (A), mesangium (B), renal tubular (C), and arterioles/arteries (D) using a 0 to 4 scoring range: 0 , absent, 1 rare, 2 low abundance, 3 moderate abundance, and 4 high abundance. SLE patients were divided into two groups based on the levels of B-cell IFN $\beta$ either below the mean (IFN $\beta$ low, $n=10$ ) or above the mean (IFN $\beta$ high, $n=13$ ) (Data are mean $\pm S E M ;$ 2-way ANOVA test on the effects of B-cell IFN $\beta$ and IC type in each region). 
A

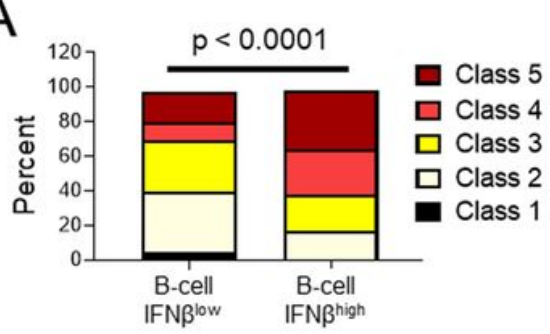

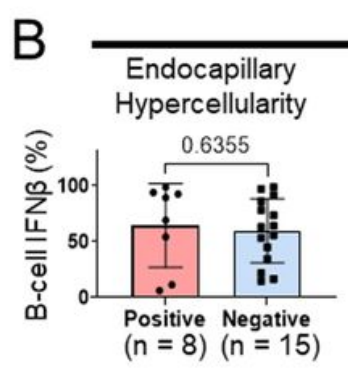

Chronic Glomerular Lesions
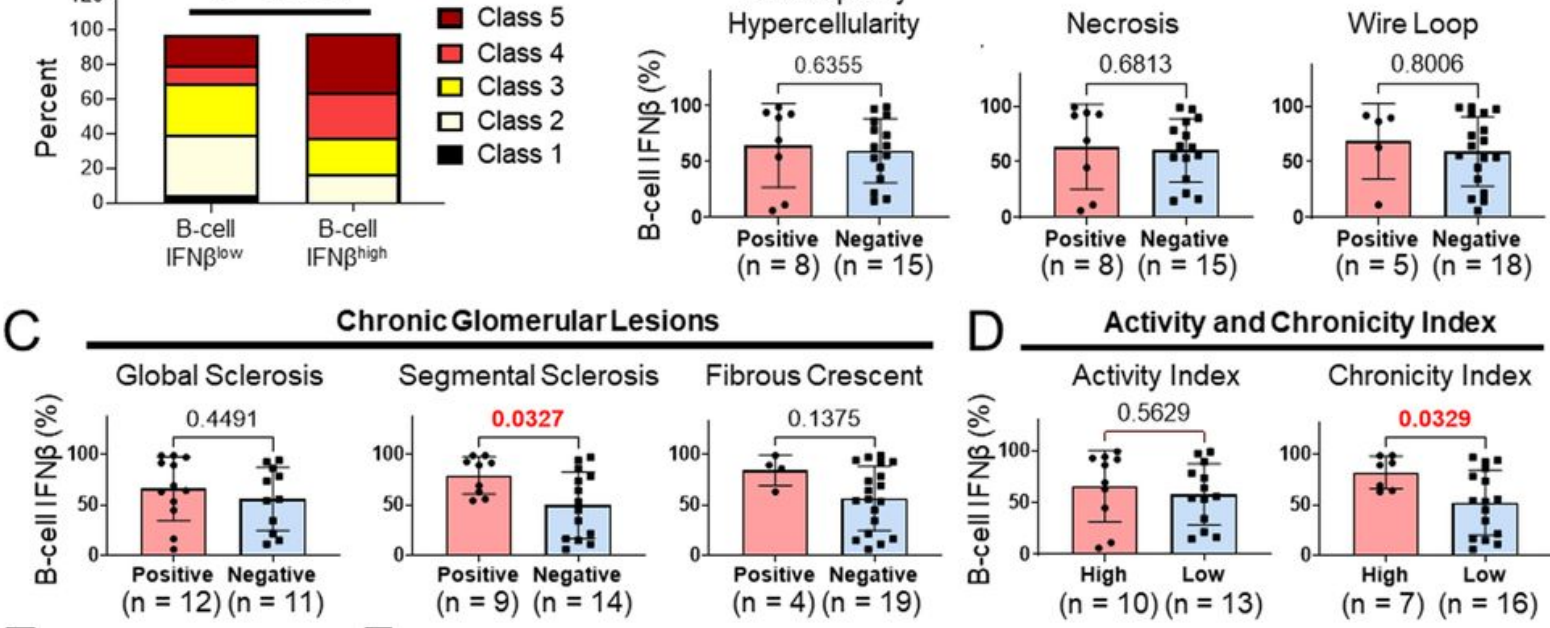

Fibrocellular Crescent

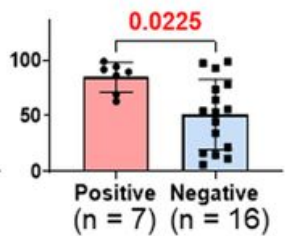

\section{$\mathrm{D}$}

Activity and Chronicity Index

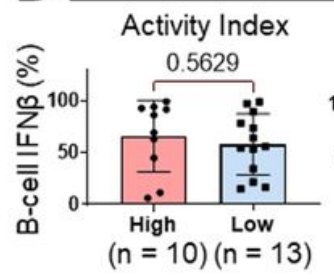

Chronicity Index

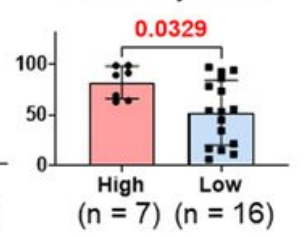

$E_{\text {Membranous pattern }} \mathrm{F}$

Tubulointerstitial lesions (Acute and chronic)
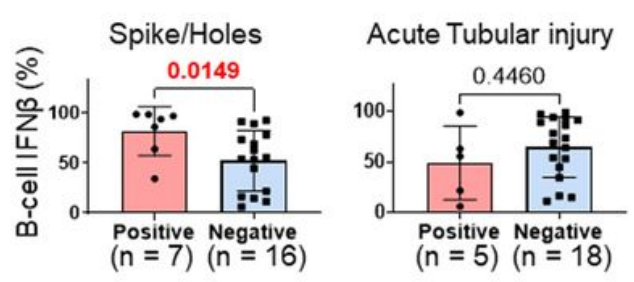

Interstitial fibrosis

and tubular atrophy

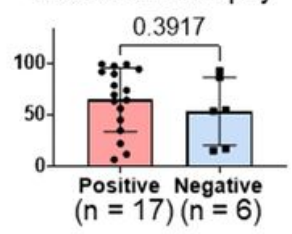

\section{Figure 5}

Quantitative analysis of renal biopsy features with B-cell IFNB. (A) The distribution of LN classification in patients with low (lower $50 \%$ ) versus high (upper $50 \%$ ) B-cell IFN $\beta$. The $p$ value (chi-squared test) is shown above the plot $(n=33)$. (B-F) The histologic features were analyzed using renal biopsy specimens available from 23 SLE patients. For each histologic features, the individual percentage of IFN $\beta+$ naïve $B$ cells was plotted for each subject and indicated by the data-point on the graph, ranging from $0-100 \%$. Histologic features associated with active glomerular lesions (B), chronic glomerular features (C), activity index and chronicity index (High: above the mean; Low: below the mean) (D), membrane patterns of spike/holes (E), and tubulointerstitial lesions (F). The p value for each comparison is indicated as the number above the groups. Red font is used to indicate the histologic features that express significantly different B-cell IFN $\beta$ for the two groups (Data are mean \pm SD; Two-tailed Mann-Whitney test). 